\title{
O DESPORTO DE NATUREZA E 0 DESENVOLVIMENTO SUSTENTÁVEL: PERSPECTIVAS DE DESENVOLVIMENTO E GOVERNANÇA
}

\author{
NATURE-BASED SPORTS AND SUSTAINABLE DEVELOPMENT: \\ PERSPECTIVES OF DEVELOPMENT AND GOVERNANCE
}

EL DEPORTE DE NATURALEZA Y EL DESARROLLO SOSTENIBLE:
PERSPECTIVAS DE DESARROLLO Y GOBERNANZA

Paulo Filipe Rosa*, Luís Alberto Dias Carvalhinho*, Jorge Alexandre Pereira Soares**

Palavras chave:

Esportes.

Natureza.

Turismo.

Desenvolvimento sustentável.
Keywords:

Sports.

Nature.

Tourism.

Sustainable development.
Palabras clave: Deportes. Naturaleza. Turismo. Desarrollo sostenible.

\begin{abstract}
Resumo: A prática de desportos de natureza é um fenómeno em crescimento. Por sua vez, o conceito de sustentabilidade, explorado na investigação em turismo, merece aprofundamento no que diz respeito ao papel do desporto de natureza no aumento da consciência ambiental, na educação e na economia. Este ensaio, cuja metodologia assenta numa revisão de literatura, foi desenvolvido com o intuito de melhor esclarecer este contributo e, face a uma reflexão crítica ao conceito de sustentabilidade, apresentar uma abordagem que contribua para a sua efetividade. A análise permitiu compreender 0 impacto económico destas atividades, assim como as necessidades de maior investimento em projetos educacionais através do desporto. Para a sua efetividade apresenta-se uma proposta de um processo de governança, que se inicia a partir das necessidades da sociedade civil e posteriormente dos restantes stakeholders e que deverá condicionar as decisões assumidas nos patamares superiores da cadeia governativa.
\end{abstract}

Abstract: The practice of nature-based sports is a growing phenomenon. In turn, the concept of sustainability, explored in tourism research, deserves greater attention regarding the role of nature-based sports as a way of increasing environmental awareness in education and the economy. This essay, whose methodology is based on a literature review, was developed in order to better clarify this contribution and, given a critical reflection on the concept of sustainability, to present an approach that contributes to its effectiveness. The analysis allowed us to understand the economic impact of these activities as well as the need for more investment in sports-based educational projects. It proposes a governance process that starts from civil society's needs and then looks into those of other stakeholders. The process should condition decisions taken at higher levels of the governance chain.

Resumen: La práctica de deportes de naturaleza es un fenómeno creciente. A su vez, el concepto de sustentabilidad, explorado en la investigación en turismo, merece que se profundice en lo referente al papel que juega el deporte de naturaleza en el aumento de la conciencia ambiental, en la educación y en la economía. Este ensayo, cuya metodología se basa en una revisión de la literatura, se desarrolló con el fin de aclarar esta contribución y realizar una reflexión crítica al concepto de sustentabilidad, presentando un enfoque que contribuya a su eficacia. El análisis permitió comprender el impacto económico de estas actividades, así como la necesidad de mayores inversiones en proyectos educacionales a través del deporte. Se presenta, para lograr eficacia, la propuesta de un proceso de gobernanza, que se inicia a partir de las necesidades de la sociedad civil y, posteriormente, de las otras partes interesadas y que debe condicionar las decisiones tomadas en los niveles superiores de la cadena de gobierno.
*Instituto Politécnico de Santarém. Escola Superior de Desporto de Rio Maior. Rio Maior, Portugal. E-mail: prosa@esdrm.ipsantarem.pt

${ }^{*}$ Universidade da Madeira. Madeira, Portugal. E-mail: j.soares@uma.pt

Recebido em: 28-11-2015 Aprovado em: 28-12-2016

(c) (1) (8) Licence 


\section{INTRODUÇÃOO}

Em 1968, Garret Hardin, famoso ecologista americano, expôs uma das primeiras manifestações públicas acerca da preocupação da relação a longo prazo entre o Homem e a Natureza. Hardin refletiu sobre os recursos comuns a todos os habitantes do planeta, denominados de "Commons". Estes se referiam aos recursos culturais e naturais acessíveis a todos os membros da sociedade, incluindo recursos como 0 ar, a água e a terra habitável. A famosa teoria econômica denominada de "The tragedy of the commons" foi publicada por Hardin em 1968 e, de acordo com este, o esgotamento de recursos (os commons) partilhados por indivíduos agindo independentemente e racionalmente de acordo com o seu interesse próprio atuaria de forma contrária aos interesses a longo prazo das comunidades. É desta perceção que advém o conceito de desenvolvimento sustentável. Impulsionado por duas importantes conferências promovidas pelas Nações Unidas (Estocolmo 1972 e Rio 1992) e devidamente mencionado em 1987, num report publicado pela World Comission on Environment and Development (WCED) intitulado "Our Common Future", foi definido como "O desenvolvimento capaz de satisfazer as necessidades do presente sem comprometer a capacidade das gerações futuras de suprir as suas próprias necessidades" (WORLD COMMISSION ON ENVIRONMENT AND DEVELOPMENT, 1987). É a partir da década de 1970 que o conceito de desenvolvimento sustentável se começa a embrenhar na mente da sociedade, assente em três pilares fundamentais: 0 económico, 0 ambiental e 0 social.

Face ao preâmbulo apresentado, pretendemos, neste ensaio, refletir sobre o papel do desporto no que respeita ao contributo para os diferentes pilares da sustentabilidade. 0 ensaio resulta de vários anos de reflexão e pesquisa relacionados com esta temática e visa evidenciar caminhos, novos ou ainda carecentes de investigação, assim como áreas específicas de conhecimento que são atualmente necessárias para uma melhor compreensão do fenómeno desportivo. Focamo-nos mais especificamente no desporto de natureza (DN) com ênfase nas práticas associadas ao fenómeno turístico, nas vertentes de aventura e natureza. 0 conceito de sustentabilidade, bastante explorado na investigação na área do turismo, merece maior aprofundamento no que diz respeito ao papel do desporto de natureza e aventura enquanto prática de lazer, como meio para a educação e como produto comercial do turismo. Queremos com isto dizer que uma aparente e fácil inclusão das atividades desportivas de natureza dentro dos âmbitos da educação, recreação ou do turismo não justifica, por si só, a sua pertinência para a sustentabilidade, já que princípios de desenvolvimento e contributos destas atividades devem ser evidenciados.

Esta reflexão cruza resultados empíricos que revelam a importância das práticas de DN para o desenvolvimento sustentável, com uma abordagem crítica a este mesmo conceito. Culmina com recomendações úteis para alguns problemas que se evidenciam, assentes num processo de governança em que se defende uma clara aproximação bottom-up. Em termos metodológicos, a revisão de literatura foi organizada de acordo com as dimensões de sustentabilidade, nomeadamente econômica, ambiental e social e com uma tendência cronológica que permitiu analisar sinais de constância e desenvolvimento deste fenômeno. Em primeiro lugar, procurou-se complementar a existência de estudos empíricos, de natureza científica, com outros documentos de natureza institucional que remetem para políticas de

1 Turismo de Aventura - Uma viagem turística que inclui pelo menos dois de três elementos: atividade física, ambiental natural e imersão cultural (ADVENTURE TRAVEL TRADE ASSOCIATION, 2013). 
desenvolvimento sustentável (e.g. Carta Europeia do Desporto) ou reports internacionais relacionados com o turismo (e.g. reports UNWTO). Em segundo, os estudos analisados estão situados entre os anos de 1999 e 2014, o que contribuiu para a análise da constância de resultados (em especial ao nível do pilar económico). Em terceiro, existiu a preocupação de obter resultados que caracterizassem diferentes locais do globo, numa tentativa de aferir a similaridade de resultados em diferentes contextos nacionais e regionais. Por último, os documentos foram obtidos com recurso à internet, através do motor de busca Google Acadêmico e através da consulta direta a websites de periódicos internacionais de grande relevância. Como premissa para seleção dos estudos para leitura primária, considerou-se, além da ligação com o tema em estudo, a devida publicação em periódicos e/ou livros editados, rejeitando-se quaisquer documentos não publicados oficialmente ou textos de opinião.

\section{DESPORTO DE NATUREZA E O PILAR ECONÓMICO}

Documentos de base na organização do desporto focaram, desde o início, a relevância destas práticas para desenvolvimento socioeconómico. Exemplo claro é a Carta Europeia do Desporto (CED), referindo que ele "Pode também contribuir para o desenvolvimento local e regional, a regeneração urbana e o desenvolvimento rural" (CONSELHO DA EUROPA, 1992, p. 3, p. 11) ${ }^{2}$. Na realidade, diversos autores têm sugerido o crescimento da importância destas atividades, essencialmente visível no número de adeptos crescente (SOARES; PAIXÃO, 2010) na fuga de centros urbanos e em busca de paisagens idílicas (BRASIL; CARVALHO, 2009). Estas assunções são fortalecidas no trabalho de Rosa, Carvalhinho e Soares (2014), associadas à evolução do DN na sociedade, inicialmente como prática de lazer e, posteriormente, como manifestação dos mercados da recreação e do turismo, sobretudo nos segmentos ativos e de aventura. Neste domínio, o turismo é, sem dúvida, uma das economias que melhor acolheu e potenciou o desenvolvimento económico destas práticas, sobretudo em espaços naturais, contexto em que centramos seguidamente a nossa atenção.

Nos segmentos mais ativos de prática turística (turismo ativo e de aventura), a ênfase deve ser dada aos turistas que viajam com o intuito de participar em atividades desportivas e de lazer, em grande parte na natureza, traduzindo-se em atividades relacionadas com a água, montanha, o golfe, o tênis, etc. (KOUTHOURIS; ALEXANDRIS, 2005). De acordo com os mesmos autores, referindo-se ao mercado europeu, mais especificamente à realidade grega, a partir de 1990, e face ao crescendo da procura, a "indústria" ganhou uma maior estabilidade. Novas organizações privadas relacionadas com o outdoor surgiram no mercado e algumas se organizaram seguindo os princípios de franchising. 0 mercado aumentou significativamente em resultado das tendências socioeconômicas e do estilo de vida. Aqui, as tecnologias de comunicação assumiram também um papel relevante. Verificou-se um aumento na participação em atividades na natureza, associado a um estilo de vida mais ativo e alternativo para a generalidade dos indivíduos, famílias e membros de associações. As organizações privadas tornaram-se cada vez mais profissionais, focadas na receção de turistas locais e internacionais, com ênfase na criação e desenvolvimento de uma rede de distribuição (KOUTHOURIS; ALEXANDRIS, 2005).

Provas desta evolução foram verificadas no trabalho de Ditton e Baker (1999), que, focados nos benefícios económicos do mergulho, reconheceram importantes ganhos 
económicos para as comunidades locais, particularmente ao nível do aluguer de embarcações para aceder aos locais de prática. Na mesma altura, em Espanha, Betrán e Betrán (1999) verificaram que a Catalunha se havia tornado um local ideal para a prática de atividades de DN, devido à existência de uma rede de negócios importante, que respondia a uma demanda crescente de utilizadores. A tradição "caminhante" e escaladora, a topografia, o desenvolvimento urbano e os seus contextos culturais, sociais e económicos específicos facilitaram o enraizamento deste conjunto de práticas, destacando-se como uma sólida oferta. As empresas que promoviam estas atividades organizaram uma rede de pequenos negócios, que contribuíram para a correção de determinados desequilíbrios económicos e demográficos de alguns territórios deprimidos.

Já no novo milênio, Cloke e Perkins (2002) discorreram acerca da importância da marca "Adventure" na economia Neozelandesa e o importante papel para o desenvolvimento turístico desta nação. Beedie e Hudson (2003) salientaram a emergência do turismo de montanha, dando ênfase ao caso Nepalês, cujos interesses comerciais aumentaram ano após ano e facilitaram o crescimento do turismo de aventura num país caracterizado pelas atividades de alpinismo. Tomando ainda como exemplo o turismo de montanha, também Bourdeau, Corneloup e Mao (2002), ao estudarem o caso francês, assumiram que, particularmente no verão, a renovação da oferta desportiva contribuiu para a revitalização do turismo de montanha, e que este facto é o centro do sistema turístico na região.

Há mais de uma década, em alguns locais do globo, o turismo de surf chegou a uma escala econômica de relevo, trazendo consigo importância econômica, social e ambiental para as comunidades das ilhas do Indo-Pacífico (BUCKLEY, 2002). $O$ autor concluiu que o turismo de surf era uma nova influência para esta região, e, fazendo parte de uma multibilionária "indústria" do turismo de aventura mundial, tinha o potencial de lhes proporcionar uma fonte de receita a longo prazo num mercado em franco crescimento.

Já no final da primeira década do novo milénio, outras referências (MARINHO, 2008; PRÖBSTL et al., 2010) remetem para tendências de procura crescente destas práticas em meio natural. Exemplo disso foi a pesquisa de Hill, Cable e Scott (2010), ao demonstrar que as atividades turísticas focadas na natureza e na vida selvagem, como foi o caso da observação de aves, eram responsáveis por um substancial desenvolvimento e ampliação do mercado mundial do turismo, enquanto a caça e outras formas de uso/consumo da vida selvagem estavam em queda. Os autores concluíram que estes indivíduos, necessitando de momentos de escape, alojamento, suprimentos e equipamentos, eram um mercado a ser explorado. Constituem, além disso, um motor económico, que pode ser lucrativo para as comunidades, e um incentivo à visitação e ao fornecimento de produtos e serviços de observação de aves.

Segundo Boutroy, Bourdeau, Mao e Senil (2012), a região de Rhône-Alpes é reconhecida hoje como um exemplo neste campo. Caracteriza-se por uma concentração excecional de organizações desportivas e é um líder nacional no subsetor de natureza e desportos de montanha, tanto em termos de espaços desportivos, locais de prática, itinerários e suporte profissional, como em termos de treino e formação, investigação, distribuição especializada ou meios de comunicação. Esta se constitui assim como uma região emblemática, que é sistematicamente colocada na vanguarda da oferta nacional, no que se refere a desportos de montanha.

Retomando o caso do surf, verifica-se que este gera hoje uma economia de grande escala, podendo-se tomar como exemplo desse desenvolvimento a existência de uma etapa 
do circuito mundial na cidade de Peniche e o impacto económico considerável na região oeste de Portugal (INSTITUTO POLITÉCNICO DE LEIRIA, 2012).

Se considerarmos dados provenientes do setor turístico, cuja influência sobre 0 crescimento dos DN é também evidente, constatamos que, a nível internacional, e de acordo com a International Ecotourism Society, o ecoturismo tem sido alvo de um crescimento anual de $15 \%$, o que significa quatro vezes mais do que outras formas mais tradicionais de turismo. O ecoturismo e o uso da biodiversidade revelam-se como uma oportunidade de negócio promissora (WORLD TOURISM ORGANIZATION, 2012) e, por conseguinte, os DN poderão ser influenciados por estas tendências. No que diz respeito ao turismo costeiro, verifica-se também um crescimento significativo na procura de experiências pelos turistas. Tradicionalmente conetado à passividade e ao produto "Sol e mar", algumas das novas tendências incluem: i) maior procura de atividades recreativas e desportivas como o snorkelling, mergulho, windsurf, passeios de barco; ii) a procura de locais com maior qualidade ambiental (natureza); iii) maior interesse na natureza e no visionamento da vida selvagem; iv) maior interesse em atrações culturais (WORLD TOURISM ORGANIZATION, 2013). Apesar de os dados a este nível não evidenciarem na sua totalidade as práticas desportivas, algumas das tendências apresentam clara possibilidade de inclusão dessas atividades.

O culminar dessa evolução é verificado no recente report publicado pela UNWTO intitulado Global Report on Adventure Tourism, o primeiro dessa instituição especialmente dedicado ao turismo de aventura. É importante destacar que em 2012 o turismo global ultrapassou a marca de 1 bilião de viagens e o turismo de aventura foi um dos segmentos em maior crescimento (WORLD TOURISM ORGANIZATION, 2014). De acordo com o documento, em 2010, o primeiro estudo de mercado sobre o turismo de aventura a uma escala global verificou que o valor global deste segmento era de 89 biliões de dólares americanos. 0 estudo foi repetido em 2013 e revelou que $42 \%$ dos viajantes globais viajaram num contexto de aventura, fazendo o setor valer cerca de 263 biliões de dólares, o que representa um aumento de 195\% em dois anos. O mesmo report refere ainda os enormes benefícios económicos para as regiões de destino, na criação de emprego e geração de receita.

A pesquisa por estudos realizados em datas muito distintas (com intervalos de cerca de 14 anos) não surge por acaso. Os resultados revelam que estas práticas, mesmo representativas de um mercado jovem, estão instauradas há vários anos e continuam a crescer e a revelar-se importantes fontes de rendimento local em alguns destinos. 0 caso mais emblemático é vivido na Nova Zelândia, onde a cultura dos DN se congratulou como imagem deste destino turístico, assumindo assim uma dimensão nacional (CLOKE; PERKINS, 2002). Para além deste, outros países tem assumido a "aventura" na identidade da sua marca, como é o caso da Noruega, Groenlândia ou Eslovénia (WORLD TOURISM ORGANIZATION, 2014).

Cabe-nos ressalvar algumas considerações importantes: 1) o mercado do DN apresenta evidências de impacto económico a nível local ou regional; 2) este mercado aumenta ainda a sua dimensão se nos afastarmos dos setores da recreação e do turismo (e.g. marcas; equipamentos; eventos) (ROSA et al., 2014); 3) o seu impacto económico não se resume somente a uma visão vertical (assente unicamente na criação e fornecimento de produtos turístico-desportivos) no sentido em que deve também ser perspetivado sob uma visão horizontal, já que afeta direta ou indiretamente outros serviços (e.g. alojamento; refeições; cultura); 4) está em constante evolução no sentido da especialização, e deve adaptar-se à 
variedade de motivações dos visitantes; 5) este mercado tem um caráter predominantemente experiencial e as motivações de procura não se resumem à prática de atividade física.

Face a estas considerações, parece-nos que os seus limites de crescimento são difíceis de estabelecer, porque dependem em grande parte das motivações dos visitantes e, consequentemente, da capacidade criativa dos promotores. No entanto, um fator congratulase como excecional, já que é basal na sua génese: os recursos naturais. A degeneração dos recursos utilizados nas práticas desportivas, e ao mesmo tempo da própria paisagem, é o fator de maior importância neste mercado sobre o qual centramos a nossa atenção de seguida.

\section{O DESPORTO DE NATUREZA E O PILAR AMBIENTAL}

As práticas recreativas e turísticas em contato com o meio natural são dependentes dos recursos naturais, já que estes se revelam (a vários níveis) indispensáveis para o setor, e o DN ée será influenciado pelas alterações verificadas nos diversos ecossistemas onde é desenvolvido. Neste campo, um fator relevante que ocupa a agenda da investigação atual, sobretudo ao nível do turismo, é a relação entre o futuro destas práticas e as alterações climáticas (SCOTT; LEMIEUX, 2010; PRÖBSTL; HAIDER, 2013). A prática desportiva em contato com a natureza é dependente das características do território natural e uma evidência empírica desta realidade é traduzida, por exemplo, no recuo dos glaciares do vale de Chamonix (Alpes Franceses), que alteraram a paisagem desta região nos últimos anos e que muito provavelmente poderão influenciar as tendências de prática desportiva (e.g. travessia de glaciares; escalada em gelo, etc.).

Stenseke (2012) refere que muito da pesquisa realizada no campo da interação entre a recreação na natureza e a sua conservação tem-se concentrado principalmente sobre as suas consequências negativas para a generalidade do meio natural. Estudos no âmbito de ecologia da recreação (MARION, 1998; MARION; OLIVE, 2006; PINTO et al., 2008) refletem esta assunção. Questões relacionadas ao lixo, à poluição e à perda de coberto vegetal são exemplos de um discurso de "perturbação" que se verifica em diversos trabalhos. Assim, temse vindo a compreender que diferentes atividades desportivas de natureza têm diferentes impactos ambientais. Estes não são homogéneos ou estritamente dependentes do número de praticantes, já que variam de acordo com padrões de atividade e comportamento em geral (STENSEKE, 2012). Este fator comportamental está notoriamente relacionado com a conduta dos praticantes ou dos visitantes. Um fator resultante desta assunção está na adoção de programas ou elementos de sensibilização em áreas protegidas (MARION; REID, 2007), que fazem frente, ou complementam, a adoção de medidas de proteção mais diretas/restritivas.

Mas de uma forma um pouco paradoxal, face ao exposto, a realidade é que a recreação e o turismo em contato com a natureza têm sido apontados como meios para promover o desenvolvimento local apoiado na proteção da natureza, proporcionado uma situação vantajosa quer para as autoridades de conservação, quer para as comunidades locais (STENSEKE, 2012). Mas tendo estas atividades um caráter perturbador, de que forma poderá a assunção da autora fazer sentido?

A resposta não estará provavelmente nas ciências naturais, mas antes em aspetos que conduzem para a relevância dos fatores educacionais, de sensibilização e de consciência ecológica, sobretudo daqueles que promovem e desenvolvem estas atividades. 
Foi neste domínio que Rosa e Carvalhinho (2012) publicaram um ensaio que refletia sobre o papel do DN como fator educacional para o meio ambiente. Ao citar trabalhos de diversos autores, revelaram evidências empíricas do potencial do DN como metodologia de ensino para o ambiente, pelo que se recomenda a sua consulta.

Evidências semelhantes às referidas pelos autores referenciados encontram-se no estudo de Zeidenitz, Mosler e Hunziker (2007), cuja amostra foi constituída por praticantes de ski e picnickers (indivíduos que não estão na atividade motivados pela prática desportiva). Os resultados obtidos permitiram a identificação de preditores de um comportamento ecologicamente responsável em ambos os grupos. As atitudes das pessoas face à paisagem, $\mathrm{e}$ especialmente face à apreciação da sua diversidade, foram um dos mais importantes preditores da intenção de agir de forma responsável durante a prática das atividades recreativas na natureza.

No sentido de reforçar os resultados empíricos apresentados no trabalho de Rosa e Carvalhinho (2012), a WORLD TOURISM ORGANIZATION (2014) salienta a importância do turismo de aventura no incentivo à conservação. Refere que este pode igualmente aumentar a consciência pública acerca da importância de muitos bens e serviços providenciados pela diversidade biológica.

Para uma aquisição efetiva desta consciência, é necessário o contato continuado com estas práticas, não limitado apenas à aquisição de competências teóricas e de forma pontual. Esta aproximação é traduzida na prática com base nos princípios do ensino experiencial e situado, exemplificados nos resultados de diversos autores (LAVE; WENGER, 1991; JENSEN; SCHNACK, 1997; LIGHT, 2006; SANDELL; ÖÖHMAN, 2010).

Sem descurar da importância que cada ser vivo (ou não vivo) desempenha no equilíbrio de cada ecossistema, a conservação da natureza é acima de tudo um fenómeno social, caracterizado pela vontade do ser humano em proteger e valorizar a vida e outros aspetos de natureza moral ou estética, como é o caso da paisagem. Por isso mesmo, a educação deve ser um fenómeno que deverá acompanhar as políticas de conservação e novos modelos educacionais que privilegiem o contato com a natureza deverão ser potenciados.

No entanto, o poder educacional das atividades de DN não se resume ao ambiente. De acordo com Extremera e Gallegos (2008), estas possibilidades educacionais estão em crescimento. Cada vez mais, novos métodos e modelos de trabalho são voltados para os valores pessoais e sociais, a autonomia e a responsabilidade, o reconhecimento das diferenças entre sexos, o respeito e, finalmente, a educação para a cidadania. Esses fatores de natureza sociocultural concorrem para a terceira dimensão da sustentabilidade em que centramos de seguida a nossa atenção.

\section{DESPORTO DE NATUREZA E O PILAR SOCIAL}

O desporto, como meio de educação para a cidadania, está amplamente reconhecido e defendido em diversos documentos importantes na organização do desporto a nível mundial. A CED refere a possibilidade "[...] das diversas contribuições que o Desporto pode dar para 0 desenvolvimento pessoal e social, através da oferta de atividades criativas e ocupações recreativas" (CONSELHO DA EUROPA, 8., p. 2, 1992³). Não menos importante, o Livro Branco 
do Desporto refere que "O desporto apresenta igualmente possibilidades atrativas para 0 empenho e a participação dos jovens na sociedade e pode contribuir para evitar que estes resvalem para a delinquência." (COMISSÃO DAS COMUNIDADES EUROPEIAS, 2007, ponto 2.4., p. $\left.7^{4}\right)$.

Algumas das vertentes educativas fortemente associadas ao desporto em contato com a natureza são as internacionalmente denominadas "Adventure education" ou "Outdoor Learning ". Os modelos utilizados nestas vertentes são vários, e característicos dos diferentes países com tradição nesse âmbito, como é o caso dos EUA, Austrália ou os países nórdicos (ZMUDY; CURTNER-SMITH; STEFFEN, 2009). É neste sentido que resultados de alguns estudos devem ser evidenciados.

Gallegos, Juan e Montes (2005) focaram-se numa abordagem junto do público jovem, e referem que o Caminho de Santiago (Espanha) se revelou numa estrutura intercultural, de formação, reflexão e comunhão para a juventude em todo o mundo, especialmente para os jovens espanhóis e do resto da Europa. De acordo com os autores, a realização dessa conhecida rota envolve a juventude numa grande aventura, que permite vivenciar a prática de atividades físicas em plena natureza. Verificaram que a experiência final atende às expectativas iniciais dos jovens e que muitos consideram voltar a realizar a rota. Light (2006), partindo do conceito de "Situated Learning", verificou que a frequência e a vivência num clube de surf australiano por jovens adolescentes eram essenciais para a formação da sua identidade a vários níveis, bem como na melhoria da sua relação com a sociedade. Bahia e Sampaio (2007) referiram ainda que não é possível reduzir as práticas e as atitudes dos praticantes de DN ao simples "gosto pela aventura" e por "adrenalina", visto que alguns demonstraram perceber as possibilidades de mudança de comportamentos na sua vida citadina, quer no trabalho quer na família. Zmudy, Curtner-Smith e Steffen (2009) verificaram que as crianças que participam nos processos de educação outdoor têm diferentes aprendizagens com diversos níveis de sucesso. Não obstante, todas retiram benefícios positivos dessa aprendizagem, os quais facilitam as suas relações interpessoais.

Sandell e ÖÖhman (2010) observaram resultados que conduziam para o aumento da capacidade prática dos indivíduos com histórico de envolvência nestas atividades, assim como uma maior disponibilidade para a reflexão acerca de problemas do presente, da vida quotidiana e da sociedade em geral. Burnik e Mrak (2010), numa abordagem ao montanhismo como prática relevante de educação na natureza, fazem referência à adequação desta a dois níveis distintos: em primeiro lugar, referem que um dos princípios mais importantes da ética dessa modalidade é a regra da verdade, o que significa que os montanhistas são obrigados a comunicar os seus feitos de acordo com ela. Em segundo, consideram que os montanhistas estão conscientes da sua responsabilidade na proteção das montanhas. Às crianças e aos jovens envolvidos nestas atividades é providenciado este sentido ético e de responsabilidade ambiental.

Outro aspeto educacional, não conectado diretamente com questões de cidadania, está implícito nos princípios de desenvolvimento motor e psicomotor das crianças e jovens, a integração em grupos sociais e o respeito mútuo. Tendo em conta um conjunto de necessidades

4 EUROPEIAS, C. D. C. Livro Branco do Desporto. 2007

5 Adventure Education - Refere-se às implicações educacionais que são percebidas como tendo elementos de risco pessoal, social ou psicológico. 
locais, a NSA (National Sport Academy de Sofia) desenvolveu um campo de férias de cariz desportivo inclusivo, para crianças e jovens com deficiência. Djobova e Dasheva (2011), autoras de um trabalho inserido neste evento, referem que estes campos são ambientes onde as crianças podem aprender novas habilidades, construir amizades e experimentar 0 crescimento pessoal. As crianças e os jovens que frequentaram este campo têm diferentes tipos de deficiência, que variam de leve a grave e vivem em diferentes tipos de configurações (e.g. famílias ou instituições sociais). Em termos de atividades, a ênfase principal recaiu nos desportos aquáticos, como a natação, a canoagem, o remo e a vela. Dos resultados que advêm da análise das autoras face a este evento, são de destacar: 1) o acampamento ofereceu um exemplo de inclusão real e sustentado que poderia ser transferido dentro da comunidade em geral; 2) os participantes com deficiência evidenciaram melhorias nas suas habilidades no campo do desporto, ao nível das técnicas desportivas já assimiladas e na aquisição de novas competências; 3) os participantes com deficiência evidenciaram melhorias na autoestima e confiança.

Neste campo, Aziz e Said (2012) referem, num estudo incidido em crianças do 1ํㅜㄷㅇ, que estas se estão a tornar cada vez menos egocêntricas e mais socioexcêntricas nestas idades, dado que têm uma maior compreensão da sua relação com os outros, especialmente quando estão a "jogar" no exterior. "Jogar" no ambiente ao ar livre oferece várias possibilidades de estimulação dos seus sentidos e evolução das suas habilidades cognitivas. Estas crianças também revelam a capacidade de demonstrar as suas preferências face aos locais e às atividades que desenvolvem, já que beneficiam da crescente liberdade de brincar ao ar livre sem supervisão dos adultos (AZIZ; SAID, 2012).

Ao entrar no campo da saúde, podemos constatar que os benefícios da prática de exercício e atividade física estão já amplamente estudados, existindo provas das melhorias na qualidade de vida das pessoas que o praticam. Mas, mais especificamente, alguns autores têm vindo a evidenciar resultados positivos na qualidade física e psíquica daqueles que se envolvem na natureza e, em especial, através do desporto (TAHARA; CARNICELLI FILHO, 2009; SANDELL; ÖÖHMAN, 2010; AZIZ; SAID, 2012; BENTO, 2014).

Ardahan (2012), por exemplo, concluiu que a participação em DN tem um impacto positivo sobre a satisfação com a vida (Life Satisfaction), através da verificação de diferenças em todas as subdimensões de variáveis demográficas entre praticantes de DN e não praticantes. Degenhardt et al. (2011) referiram que a exposição à natureza contribui para o bem-estar geral e para a saúde dos indivíduos, e que as investigações indicaram uma série de benefícios físicos, emocionais, cognitivos, sociais, educacionais e espirituais associados à recreação na natureza. Face a esses resultados, sugeriram que um acesso rápido dentro das cidades a diversas áreas de lazer e a disponibilização de informação espacial (como a localização dos espaços) de fácil utilização podem ser formas de potenciar uma prática recreativa frequente por parte da população trabalhista. Bahia e Sampaio (2007) defenderam que, na busca de momentos de lazer na natureza através dos DN, é possível verificar atitudes "compensatórias", ou seja, um comportamento de fuga das dificuldades vividas no quotidiano de cada indivíduo e a falta de compreensão das possibilidades ampliadas de vivência de novos valores, que possibilitem a convivência com a natureza e com os seus pares. Um estudo realizado na Finlândia (TYRVÄINEN et al., 2006) revelou que os sintomas de stress e autoperceção da saúde são influenciados positivamente pelo tempo despendido em áreas naturais. No mesmo sentido, outros revelam que um contato semanal com a natureza torna-se influenciador do aumento das emoções 
positivas e decrescimento das análogas (BELL et al., 2005). No contexto do turismo, Rodrigues, Kastenholz e Rodrigues (2010) referem que o pedestrianismo é uma atividade apropriada no que diz respeito à sua integração num contexto turístico, relacionado com a saúde e o bem-estar, setor este em franco crescimento. Outros resultados pertinentes neste domínio são verificados na revisão de estudos efetuada por Bento (2014).

\section{REFLEXÃO CRÍTICA FACE AO CONCEITO DE SUSTENTABILIDADE}

As evidências anteriores permitem-nos considerar a efetividade do DN face ao contributo para os três pilares da sustentabilidade. Contudo, antes de tecer recomendações que potenciem o contributo dessas práticas para os domínios em estudo, é importante perceber em que medida elas devem ser situadas, e isso implica a compreensão do próprio conceito de sustentabilidade e alguns dos constrangimentos a este associado.

O conceito de desenvolvimento sustentável não é simples, nem tanto amplamente aceito, dadas as inúmeras discussões em seu torno e de um aspeto fulcral: a transposição de um conceito teoricamente coerente para a prática efetiva, cuja descrição tem sido assente num complexo normativo, de forma imprecisa e não operacional (HUNTER, 2002; MCKERCHER, 20037; SAARINEN, 2006). Neste espetro, inúmeras são as análises e questões colocadas. Há mais de uma década, Sharpley (2000) levantou algumas questões que estão fortemente interrelacionadas, tais como: o papel do crescimento económico na promoção do bem-estar humano; a substituibilidade do capital de recursos naturais com o capital criado pelo homem através do crescimento económico e inovações tecnológicas; a capacidade das novas tecnologias e métodos de gestão ambiental para dissociar o crescimento económico da degradação ambiental; o significado ou o valor atribuído ao mundo natural e os direitos de espécies não humanas.

De forma análoga, também Ryan (2002) levantou questões pertinentes: " $E$ se a sustentabilidade é percebida como uma retenção do status quo para proteger um ambiente cultural ou físico, mas não reconhece a equidade social inerente a essas situações atuais? O que é feito dos pobres de determinadas regiões que não têm oportunidades económicas, educacionais ou sociais? Quem vai negar o potencial do avanço económico para os filhos de agricultores de subsistência em razão da proteção de ambientes naturais ou tradições culturais e rurais?" Hunter (2002), de forma semelhante, questionou até que ponto se poderá justificar um crescimento económico continuado em países desenvolvidos, onde as necessidades básicas já estão cumpridas e as condições de bem-estar já equivalem à satisfação dos desejos dessas mesmas sociedades?

À imagem das questões levantadas pelos autores, verifica-se que o debate sobre 0 desenvolvimento sustentável levanta inúmeras discussões entre os comentaristas académicos, concorrendo para isto, provavelmente, a sua transversalidade a todos os setores da economia.

Saarinen (2006) refletiu sobre três grandes "tradições" subjacentes à compreensão do conceito dentro do campo turístico, numa perspetiva de aplicação regional/local: a) Resource Based Tradition, b) Activity-based tradition, c) Community-based tradition, e reconheceu que todas estas perspetivas têm as suas vantagens, mas também limitações e resultados diferentes. A Activity-based tradition demonstra a presente e relativamente aceita hegemónica ideia de 
sustentabilidade. Esta reflete o turismo como um instrumento para o desenvolvimento, que pode contribuir para a sustentabilidade, mas que representa fortemente a perspetiva do setor, para quem o crescimento e suas necessidades são condições para justificar a sustentabilidade: o objetivo e a força motriz é a sustentabilidade do turismo e dos recursos de base para as necessidades futuras deste setor económico. Neste caso, o meio ambiente, as comunidades locais e as culturas são os recursos.

Apesar da verdade certamente incontestável de que a magnitude e a natureza do desenvolvimento da economia turística em quase todas as áreas são (ou serão) afetadas por uma grande variedade de outros tipos de desenvolvimento existentes (e previsíveis) (e.g. habitação, transportes, fornecimento de serviços de saúde, a conservação da natureza ou a agricultura), elas se caracterizam pela abundância de planos, estratégias, modelos e estruturas construídas exclusivamente, ou quase exclusivamente, do ponto de vista do turismo (HUNTER, 2002). Provavelmente como resultado de problemas conceituais, desconcordâncias e a multidimensionalidade de ambos os conceitos, muitos académicos concordam que uma exata definição de turismo sustentável não existe (SAARINEN, 2006).

É importante que nos questionemos acerca de um fator que se releva da reflexão realizada: será que a necessidade de sustentar os recursos da "indústria" do turismo está sempre de acordo com as necessidades de sustento dos próprios recursos em si? Ou até com as próprias necessidades das populações que habitam nos locais de destino?

O desenvolvimento sustentável não pode assim ser visto como um código rígido, mas antes como um paradigma flexível ou adaptável, em que diferentes caminhos de desenvolvimento possam ser adequados de acordo com as condições locais. Assim, a sustentabilidade deve estar primeiramente conectada com as necessidades das pessoas, não com as necessidades de uma certa indústria, e o uso dos recursos naturais e culturais deve ser salvaguardado de forma a garantir as necessidades humanas no futuro. Embora seja por vezes expectável, as necessidades das pessoas e de um qualquer setor económico não têm de estar necessariamente em conflito e, neste campo, o turismo de aventura pode ser uma fonte de benefícios para o desenvolvimento das regiões de destino e a participação ativa dos intervenientes numa comunidade deve ser um elemento contributivo para a resolução de possíveis conflitos e tomadas de decisão (SAARINEN, 2006).

\section{CONSIDERAÇÕES FINAIS}

Num sentido conclusivo, face ao exposto ao longo deste ensaio, parecem-nos evidentes as potencialidades do DN como elemento contribuidor para o desenvolvimento sustentável da sociedade. Encontramos, antes de mais, uma prática em crescimento, que ocupou uma posição determinante na ocupação do tempo de lazer das populações. É esta tendência das novas sociedades que nos permite realizar uma reflexão final acerca do papel dos DN dentro de cada uma das dimensões de sustentabilidade:

1) A evolução das sociedades e das indústrias que a constituem fazem emergir o turismo, como setor económico com impacto mundial. Neste escopo, e tendo em conta os segmentos do turismo ativo, de aventura e natureza, o DN revela sinais de uma real contribuição para as economias rurais e, em alguns casos, assume relevância regional (caso dos Alpes Franceses) ou nacional (caso Neozelandês). 
2) O DN não deve ser unicamente entendido como produto final de consumo, mas também como complemento a outras atividades de natureza mais cultural ou contemplativa, por turistas e/ou visitantes que nem têm a motivação desportiva como principal. Isto sucede numa vertente mais soft das práticas, traduzidas, por exemplo, pela prática de pedestrianismo ou canoagem em águas calmas. Outro fator de elevada importância está relacionado com a dimensão horizontal do impacto destas atividades. $O$ turismo de aventura implica, na maior parte das vezes, o consumo de outros serviços e produtos turísticos (ou não turísticos), sendo os mais evidentes o alojamento e as refeições, que podem contribuir assim para um maior desenvolvimento local. É por isso que governos e instituições locais devem promover a organização do sistema turístico, numa tentativa de evitar situações de crowding, desigualdade no acesso e distribuição da rendibilidade, e na correta promoção deste setor em áreas com potencial, mas que, pela existência de outros setores económicos mais poderosos podem estar suprimidas.

3) Em termos ambientais, não será sensato da nossa parte negligenciar os potenciais impactos negativos destas práticas (como acontece, aliás, com todas as atividades humanas). Sensato será considerar que o praticante/visitante/utilizador ou o turista é o principal veículo ou causador desse mesmo impacto, e que a consciência ecológica de cada indivíduo é um fator basal para a minimização dos efeitos negativos das suas ações. É neste campo que o DN pode providenciar experiências de elevada qualidade e profundidade, permitindo a experimentação contínua, a reflexão e, posteriormente, uma adoção de comportamentos cada vez mais aceitáveis face ao meio ambiente. Seja no ambiente escolar, desportivo (associativo) ou turístico, as possibilidades de implementação das práticas desportivas na natureza são enormes e as áreas protegidas, por exemplo, como símbolos do respeito e ideal de conservação, podem ser palcos de prática por excelência.

A existência de pouca atenção governamental na promoção desses valores ao nível da educação e a tradição do fomento de políticas tendencialmente conservacionistas, como no caso das áreas protegidas e classificadas (ROSA, 2014), são situações que deverão ser alteradas, com base na providência, através da cooperação entre os setores associados ao DN (turismo, ambiente, desporto, etc.), de programas de envolvência das pessoas na natureza em especial no ambiente escolar. Tudo isto carece de uma maior preocupação dos vários stakeholders (desde o Estado aos clubes desportivos) para a promoção de uma educação em contato com a natureza.

4) $O$ desenvolvimento pessoal das crianças e jovens é um fator basal no desenvolvimento das sociedades. Em zonas caracterizadas pela ruralidade, esse fator ainda se pode tornar mais pertinente se considerarmos as possibilidades providenciadas pelo desporto como fator de educação para o desenvolvimento pessoal, físico e psicológico das crianças, assim como para a cidadania, o respeito pelo próximo e a socialização. Os exemplos demonstrados nos diversos estudos abordados revelam a aptidão da prática desportiva e da natureza no desenvolvimento de determinadas competências pessoais, no constructo de uma identidade própria e de acordo com os valores morais da sociedade. A este fator educacional é adicionada a já reconhecida capacidade que o desporto (na sua generalidade) providencia aos seus participantes, no que diz respeito à qualidade de vida e ao bem-estar. 0 elemento "natureza", implícito nas práticas desportivas em estudo, dá ainda mais ênfase aos efeitos benéficos da atividade física. Aqui, os benefícios não afetam apenas os mais jovens, mas também os indivíduos da classe trabalhadora que, em busca de momentos de escape, 
alívio do stress ou do cansaço, ocupam o seu tempo de lazer ou as suas viagens em espaços naturais, dentro de cidades ou não, através da vivência da natureza e da prática de DN. Se uma determinada região é alvo de procura turística ou de lazer, é porque desperta interesse no visitante. Se isto se verifica, então se presume que a área tem valor e esse aspeto contribui para uma maior valorização cultural e etnográfica dos próprios residentes, que encontram, muitas vezes, oportunidades económicas e de socialização.

Face ao exposto, e à luz das assunções tecidas quando da análise do conceito de desenvolvimento sustentável, consideramos que as necessidades das pessoas devem ser acauteladas e as entidades governamentais (regionais e locais) deverão promover programas de exercício e atividade física em contato com o meio natural, sem perder de vista a importância de novos investimentos em locais/oportunidades de prática dentro das cidades.

É por essa razão que defendemos que a prática desportiva, extravasando o seu escopo competitivo e agonista, é uma prática capaz de contribuir para o desenvolvimento da sociedade em geral. Aquela realizada em contato com a natureza, por implicar o "meio natural", traz vantagens adicionais aos mais variados níveis.

O desporto é reconhecido sobretudo pelo seu papel integrador e propulsor dos valores da sociedade e do respeito pelo próximo, valores defendidos por Pierre de Coubertin e o ideal dos Jogos Olímpicos. E é por isso mesmo que o seu contributo para o desenvolvimento sustentável não está unicamente dependente do indivíduo (o praticante) ou da política ambiental e social de determinada instituição isoladamente (à semelhança das empresas). Parece-nos assim, que esse contributo está fortemente associado a questões de governança.

A governança envolve corporações, organizações não governamentais e indivíduos. Isto quer dizer que a governança está associada ao envolvimento de outras instituições e indivíduos numa perspetiva participativa, quer ao nível do planeamento, quer da gestão.

É através desta aproximação participativa que consideramos ser possível atingir os objetivos da sustentabilidade. Consideramos o desenvolvimento da Figura 1, com o intuito de melhor expor esta aproximação.

Figura 1 - Governança

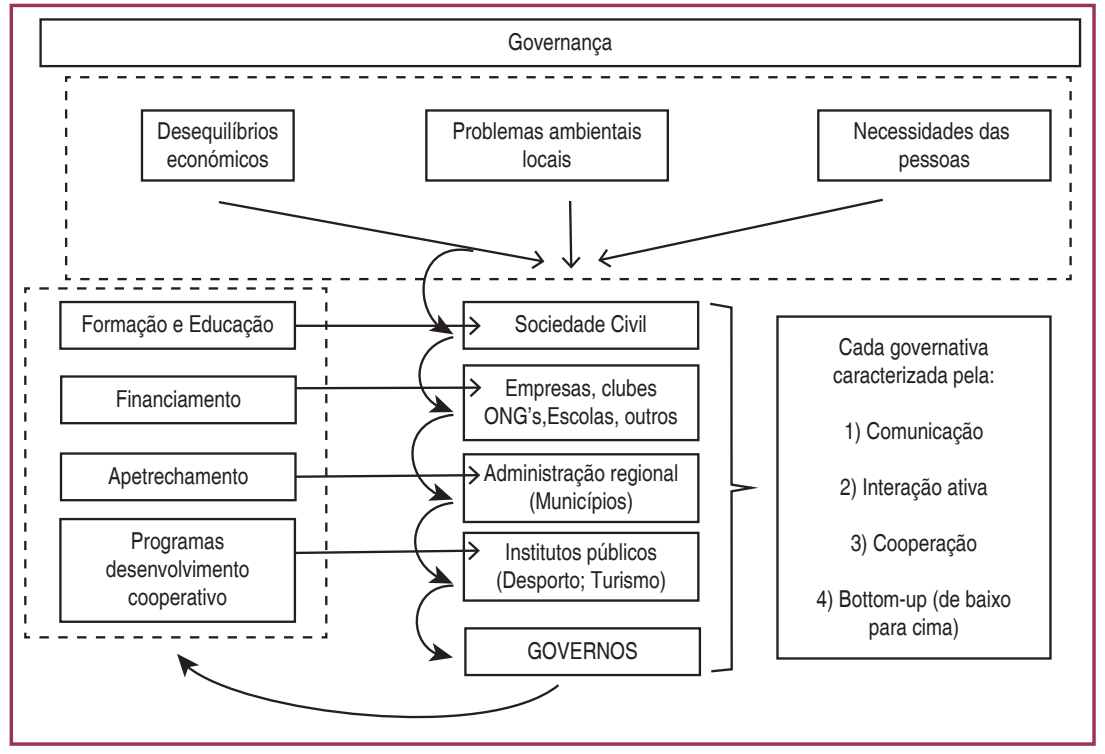

Fonte: Autores. 
$\mathrm{Na}$ figura, verificamos no primeiro quadro tracejado a referência a problemas/ necessidades associadas aos três pilares da sustentabilidade (desequilíbrios económicos, problemas ambientais, necessidades sociais).

Tendo em conta as críticas estabelecidas anteriormente face ao conceito de sustentabilidade, se defendemos que 0 desenvolvimento deve atentar às necessidades das pessoas e das regiões, então estas (Sociedade civil) devem ser alvo primário de recolha de informação. É neste nível que devemos recolher as perceções, problemas, necessidades e até possíveis soluções para os três domínios da sustentabilidade que se encontram dentro do primeiro quadro tracejado. Esta recolha de informação pode provir do trabalho conjunto entre Universidades (através da investigação), associações locais, entre outros. Posteriormente, essas informações devem ser complementadas pelas informações dos restantes elementos da cadeia participativa (Empresas, Municípios, Institutos Públicos), na medida em que a similaridade de perceções, ideias e estratégias/soluções podem contribuir para uma definição mais robusta de estratégias para o futuro. As decisões aos vários níveis da cadeia governativa devem partir do conhecimento efetivo das necessidades das pessoas, e remontando às críticas realizadas em torno do conceito de desenvolvimento sustentável, devem ter em conta as necessidades das pessoas e não do desporto per si. Neste sentido, devem ser adotadas novas ideologias e metodologias que promovam o DN, o usufruto da natureza, a interação entre diferentes pessoas e uma economia mais justa, equitativa e devidamente organizada nos destinos turísticos com potencial para a oferta destas atividades.

A promoção de ações governamentais (novamente em parceria com os restantes membros da cadeia governativa) só ocorre após esta recolha exaustiva de informação e deve ser criada de acordo com as reais necessidades identificadas anteriormente. No quadro tracejado do lado esquerdo da figura, exemplificamos algumas ações que, face ao discutido anteriormente, podiam ser aplicadas. Tomamos como exemplo o apetrechamento de espaços citadinos com novos locais de práticas de lazer em ambientes seminaturais.

De uma forma geral, a proposta apresentada defende que a determinação de ações para promover a sustentabilidade através das práticas desportivas deve ser antecipada de uma descendência de informação, proveniente, antes de mais, das pessoas (i.e. sociedade civil).

Finalizamos este ensaio fazendo sobressair a necessidade de um maior entendimento no que diz respeito à governança no desporto de natureza e à dinâmica intersectorial (desporto, ambiente, turismo, saúde, economia e educação) em que este se encontra como um caminho possível para um melhor contributo do DN para o desenvolvimento sustentável.

\section{REFERÊNCIAS}

ARDAHAN, Faik. Life satisfaction and emotional intelligence of participants/nonparticipants in outdoor sports: Turkey case. Procedia: Social and Behavioral Sciences, v. 62, p. 4-11, 2012.

ADVENTURE TRAVEL TRADE ASSOCIATION. Adventure tourism market study 2013. Adventure Travel Trade Association. 2013. Disponível em: <http://files.adventuretravel.biz/docs/research/ adventure-tourism-market-study-2013-web.pdf>. Acesso em: 18 fev. 2016. 
AZIZ, Nor Fadzila; SAID, Ismail. The trends and influential factors of children's use of outdoor environments: a review. Procedia - Social and Behavioral Sciences, v. 38, p. 204-212, 2012.

BAHIA, Mirleide Chaar; SAMPAIO, Tânia. Lazer-meio ambiente: em busca das atitudes vivenciadas nos esportes de aventura. Revista Brasileira de Ciências do Esporte, v. 28, n. 3, p. 173-189, 2007.

BEEDIE, Paul; HUDSON, Simon. Emergence of mountain-based adventure tourism. Annals of Tourism Research, v. 30, n. 3, p. 625-643, 2003.

BELL, Simon et al. Self Reported Stress Reduction by Users of Woodlands. In: GALLIS, C. Forests, Trees, and Human Health and Well-Being. Thessaloniki: SIOKIS Medical \& Scientific, 2005. p.71-80.

BENTO, Teresa. A relação entre o ambiente natural, a atividade física e a saúde: breve reflexão de estudos. In: CARVALHINHO, L. (Ed.). Desporto de natureza e turismo ativo: contextos e desenvolvimento. Rio Maior: Escola Superior de Desporto de Rio Maior, 2014. p. 77-88.

BETRÁN, Alberto; BETRÁN, Javier. Las actividades físicas de aventura en la naturaleza: estudio de la oferta y la demanda en el sector empresarial. Apunts, v. 57, p. 86-94, 1999.

BOURDEAU, Philippe ; CORNELOUP, Jean; MAO, Pascal. Adventure sports and tourism in the french mountains: dynamics of change and challenges for sustainable development. Current Issues in Tourism, v. 5, n. 1, p. 22-32, 2002.

BOUTROY, Éric et al. Combination of geographical and socioeconomic proximities: the "mountain and nature sports tourism" commodity chain in the Rhône-Alpes region. Journal of Alpine Research, v. 100, n. 3, p. 2-12, 2012.

BRASIL, Fernanda; CARVALHO, Yara. Pescadores artesanais, surfistas e a natureza: reflexões a partir de um olhar da educação física. Movimento, v. 15, n. 1, p. 217-239, 2009.

BUCKLEY, Ralf. Surf tourism and sustainable development in indo-pacific islands.l: The industry and the islands. Journal of Sustainable Tourism, v. 10, n. 5, p. 405-424, 2002.

BURNIK, Stojan; MRAK, Irena. Mountaineering as an important part of outdoor education. In: DEJAVNOSTI, C. Š. I. O. Encountering, experiencing and exploring nature in education, 2010. Ljubljana: Center Šolskih in Obšolskih Dejavnosti, 2010. p. 13-25.

CARVALHINHO, Luís; ROSA, Paulo. Enquadramento do subsetor de desporto de natureza e turismo ativo. In: CARVALHINHO, L. (Ed.). Desporto de natureza e turismo ativo - contextos e desenvolvimento. Rio Maior: Escola Superior de Desporto de Rio Maior, 2014.

CLOKE, Paul; PERKINS, Harvey. Commodification and adventure in New Zealand tourism. Current Issues in Tourism, v. 5, n. 6, p. 521-549, 2002.

DEGENHARDT, Barbara et al. Influences of personal, social, and environmental factors on workday use frequency of the nearby outdoor recreation areas by working people. Leisure Sciences, v. 33, n. 5, p. 420-440, 2011.

DITTON, Robert; BAKER, Troy. Demographics, attitudes, management preferences, and economic impacts of sport divers using artificial reefs in offshore texas waters. Texas: Texas Parks and Wildlife Department, 1999.

DJOBOVA, Stefka; DASHEVA, Daniela. Development of projects on the basis of local needs: sports projects for economic growth and community development. In: RONNIE LIDOR, K.-H. S.; KATRIN, Koenen. International Conference on Sport for Development and Peace: Sport as a Mediator 
between Cultures, 2011. Israel: International Council of Sport Science and Physical Education, 2011. p. 231-233. Disponível em: <https://www.researchgate.net/profile//rene Kamberidou/ publication/260601167 Athletes United for Peace Reconciliation through Sport pp 187-202/ links/0a85e531cb152e4d8c000000/Athletes-United-for-Peace-Reconciliation-through-Sportpp-187-202.pdf>. Acesso em: 22 jan. 2016.

EXTREMERA, Antonio; GALLEGOS, Antonio. Las actividades físicas en la naturaleza en el currículum actual: contribucíon a la educación para la ciudadanía y los derechos humanos. Retos, Nuevas tendencias en Educacíon Física, Deporte y Recreación, n. 14, p. 48-53, 2008.

GALLEGOS, Antonio.; JUAN, Francisco.; MONTES, Mํㅡㄹ Elena. El camino de Santiago, una actividad física de recreación y formación para los jóvenes. Retos, Nuevas tendencias en Educacíon Física, Deporte y Recreación, n. 7, p. 7-13, 2005.

INSTITUTO POLITÉCNICO DE LEIRIA. Grupo de Investigação em Turismo. Estudo do Impacto do Rip Curl Pro 2012 Portugal: síntese. Peniche: GITUR, 2012. Disponível em: <http://www. valueofwaves.org/uploads/1/1/4/2/11420190/relatoriosintesercppeniche2012.pdf>. Acesso em: 10 jun. 2015.

GRAY, Barbara. Strong opposition: frame-based resistance to collaboration. Journal of Community and Applied Social Psychology, n. 14, p. 166-176, 2004.

HILL, Steven; CABLE, Ted; SCOTT, David. Wildlife-based recreation as economic windfall: a rhetorical analysis of public discourse on birding. Applied Environmental Education and Communication Education, v. 9, n. 4, p. 224-232, 2010.

HUNTER, Colin. Aspects of the sustainable tourism debate from a natural resources perspective. In: HARRIS, R.;GRIFFIN, T. et al. (Ed.). Sustainable tourism: a global perspective. Oxford, UK.: Elsevier, 2002. cap. 1, p. 3-23.

JENSEN, Bjarne; SCHNACK, Karsten. The action competence approach in environmental education. Environmental Education Research, v. 3, n. 2, p. 163-178, 1997.

KOUTHOURIS, Charilaos; ALEXANDRIS, Konstantinos. Can service quality predict customer satisfaction and behavioral intentions in the sport tourism industry? An application of the SERVQUAL model in an outdoors setting. Journal of Sport Tourism, v. 10, n. 2, p. 101-111, 2005.

LADKIN, Adele; BERTRAMINI, Andrea. Collaborative tourism planning: a case study of Cusco, Peru. Current Issues in Tourism, 2002. Disponível em: <https://www.researchgate.net/ publication/233045477 Collaborative Tourism Planning A Case Study of Cusco Peru >. Acesso em: 10 May 2014.

LAVE, Jean; WENGER, Etienne. Situated learning: legitimate peripheral participation. Cambridge: Cambridge University, 1991.p. 65-79

LIGHT, Richard. Situated learning in an Australian surf club. Sport, Education and Society, v. 11, n. 2, p. 155-172, 2006.

MARINHO, Alcyane. Lazer, aventura e risco: reflexões sobre atividades realizadas na natureza. Movimento, v. 14, n. 2, p. 181-206, 2008.

MARION, Jeffrey. Recreation Ecology Research Findings: Implications for Wilderness and Park Managers. In: KIRCHNER, H. National Outdoor Ethics Conference. St.Louis, Missouri: Izaak Walton League of America, 1998. p.188-196. 
MARION, Jeffrey; OLIVE, Nate. Assessing and understanding trail degradation: results river and recreational area. Australia: National Park Service, 2006.

MARION, Jefrrey; REID, Scott. Minimising visitor impacts to protected areas: the efficacy of low impact education programmes. Journal of Sustainable Tourism, v. 15, n. 1, p. 5-27, 2007.

PINTO, Laura et al. Atividade erosiva em trilhas de unidades de conservação: estudo de caso no Parque Nacional da Serra do Cipó, Minas Gerais, Brasil. E-scientia, v. 1, n. 1, 2008. Disponível em: $<$ <ttp://www.unibh.br/revistas/escientia/>. Acesso em:10 mar. 2015.

PRÖBSTL, Ulrike et al. Introduction. In: PRÖBSTL, U.;WIRTH, V. et al. (Ed.). Management of recreation and nature based tourism in european forests. Berlim: Springer, 2010. cap. 1, p.1-9.

PRÖBSTL, Ulrike; HAIDER, Wolfgang. Challenges for outdoor recreation and nature based tourism. Journal of Outdoor Recreation and Tourism, v. 1, n. 1, p. 3-4, 2013.

RODRIGUES, Áurea; KASTENHOLZ, Elisabeth; RODRIGUES, Apolónia. Hiking as a wellness activity - an exploratory study of hiking tourists in Portugal. Journal of Vacation Marketing, v. 16, n. 4, p. 331-343, 2010.

ROSA, Paulo. Desporto, recreação e turismo em áreas protegidas: modelo de gestão participada para o Parque Natural das Serras de Aire e Candeeiros. 2014. (Tese). Madeira : Universidade da Madeira. Disponível em: <http://hdl.handle.net/10400.13/1014>. Acesso em: 10 jan.2015

ROSA, Paulo; CARVALHINHO, Luís. A educação ambiental e o desporto na natureza: uma reflexão crítica sobre os novos paradigmas da educação ambiental e o potencial do desporto como metodologia de ensino. Movimento, v. 18, n. 3, p. 259-280, 2012.

ROSA, Paulo; CARVALHINHO, Luís; SOARES, Jorge. Retrospetiva, compreensão e perspetivação do futuro do desporto de natureza. In: CARVALHINHO, L. (Ed.). Desporto de natureza e turismo ativo: contextos e desenvolvimento. Rio Maior: Escola Superior de Desporto de Rio Maior, 2014. p. 13-34.

RYAN, Chris. Equity, management, power sharing and sustainability - issues of the 'new tourism'. Tourism Management, v. 23, p. 17-26, 2002.

SAARINEN, Jarkko. Traditions of Sustainability in Tourism Studies. Annals of Tourism Research, v. 33, n. 4, p. 1121-1140, 2006.

SANDELL, Klas; ÖÖHMAN, Johan. Educational potentials of encounters with nature: reflections from a Swedish outdoor perspective. Environmental Education Research, v. 16, n. 1, p. 113-132, 2010.

SCOTT, D.; LEMIEUX, C. Weather and climate information for tourism. Procedia, Environmental Sciences, v. 1, p. 146-183, 2010.

SHARPLEY, Richard. Tourism and sustainable development: exploring the theoretical divide. Journal of Sustainable Tourism, v. 8, n. 1, p. 1-19, 2000.

SOARES, Camilo; PAIXÃO, Jairo. Atividades de aventura e educação ambiental: possibilidades nas aulas de Educação Física escolar. Efdeportes, v. 142, 2010. Disponível em: <http://www.efdeportes. com/efd142/atividades-de-aventura-e-educacao-ambiental.htm>. Acesso em: 22 jun. 2013.

STENSEKE, Marie. On the integration of outdoor recreation in nature conservation policies. Latvian Academy of Sciences, v. 66, n. 3, p. 119-128, 2012. 
TAHARA, Alexander; CARNICELLI FILHO, Sandro. Atividades físicas de aventura na natureza (AFAN) e academias de ginástica: motivos de aderência e benefícios advindos da prática. Movimento, v. 15, n. 3, p. 187-208, 2009.

TYRVÄINEN, Liisa et al. The importance of nature to Finns and the effect of the use of green areas on perceived health and restorative experiences. In: NILSSON, K.; NIELSEN, A. Urban Forestry for Human Health and Wellbeing. Copenhagen: Elsevier GmbH, 2006. Disponível em: <http://www. sciencedirect.com/science/article/pii/S1618866707000659>. Acesso em: 10 mar. 2015

WORLD COMMISSION ON ENVIRONMENT AND DEVELOPMENT. Report of the World Commission on Environment and Development: our common future. United Nations, 1987. Disponível em: <http://www.un-documents.net/wced-ocf.htm>. Acesso em: 23 jan. 2014.

WORLD TOURISM ORGANIZATION. Global report on adventure tourism. Madrid, 2014. Disponível em: <http://cf.cdn.unwto.org/sites/all/files/pdf/final 1global report on adventure tourism.pdf $>$. Acesso em:17 abr. 2015.

WORLD TOURISM ORGANIZATION. Sustainable tourism governance and management in coastal areas of Africa. UNWTO. Madrid. 2013. Disponível em: <http://www.e-unwto.org/doi/ pdf/10.18111/9789284414741>. Acesso em: 17 abr. 2015.

WORLD TOURISM ORGANIZATION. Tourism in the green economy - background report. UNWTO. Madrid. 2012. Disponível em: <https://web.unep.org/greeneconomy/sites/unep.org. greeneconomy/files/field/image/tourism in the green economy unwto unep.pdf>. Acesso em: 17 abr. 2015.

WRAY, Meredith. Adopting and implementing a transactive approach to sustainable tourism planning: translating theory into practice. Journal of Sustainable Tourism, v. 19, n. 4-5, p. 605-627, 2011.

ZEIDENITZ, C.; MOSLER, H.; HUNZIKER, M. Outdoor recreation: from analysing motivations to furthering ecologically responsible behaviour. Forest Snow and Landscape Research, v. 81, n. 1/2, p. 175-190, 2007.

ZMUDY, Mark; CURTNER-SMITH, Matthew; STEFFEN, Jeff. Student participation styles in adventure education. Sport, Education and Society, v. 14, n. 4, p. 465-480, 2009. 